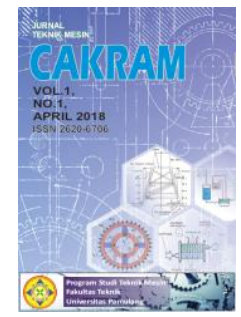

\title{
ANALISA KERUSAKAN PADA POROS DUDUKAN BOTTOM PLATE DARI MESIN PENCAMPUR CAT DAN UPAYA PENCEGAHANNYA
}

\author{
Slamet Rahardian \\ ${ }^{I}$ Program Studi Teknik Mesin, Universitas Pamulang, Jl. Surya Kencana No. 1, Tangerang Selatan, Indonesia \\ E-mail : rahardianslamet87@gmail.com
}

Masuk : 23 Mei 2020

Direvisi : 03 September 2020

Disetujui : 24 September 2020

\begin{abstract}
Abstrak: Permintaan akan Cat tembok pada pasar domestic yang tinggi menuntut penggunaan mesin yang selalu dalam kondisi prima, namun pada prakteknya sering terjadi kerusakan mesin. Salah satu komponen yang sering terjadi kerusakan adalah Poros Dudukan Bottom Plate Pada Mesin Pencampur Cat. Kerusakan tersebut mengharuskan dilakukannya penghentian proses produksi untuk melakukan perbaikan, hal ini menyebabkan kerugian waktu dan biaya bagi perusahaan. Tujuan penelitian ini dilakukan adalah untuk mencari penyebab serta mengetahui mekanisme terjadinya kegagalan yang terjadi pada Poros Dudukan Bottom Plate dengan spesifikasi material baja karbon S45C. Hasil fraktografi menunjukkan bahwa permukaan patahan merupakan struktur martensit temper yang mempunyai kekerasan cukup tinggi dan bersifat getas (brittle) sehingga tidak ada deformasi plastis pada permukaan patahan, tetapi dapat mengurangi ketahanan material terhadap beban kerja unidirectional bending dan mempunyai konsentrasi teganggan yang tinggi. Kemudian dapat disimpulkan bahwa kerusakan yang terjadi pada Poros Dudukan Bottom Plate dari material S45C pada mesin pencampur cat disebabkan oleh patah lelah (fatique fracture), hal ini didukung oleh penjalaran patah dimulai dari satu sisi shaft dan daerah fatigue terjadi pada $3 / 4$ dari diameter Poros Dudukan Bottom Plate.
\end{abstract}

Kata kunci: Poros Dudukan BottomPlate, Mesin Pencampur Cat, Analisa Kerusakan, Pengujian.

\begin{abstract}
The high demand for wall paint in the domestic market demands the use of machines that are always in prime condition, but in practice engine breakdowns often occur. One of the components that often gets damaged is the Bottom Plate Mount Shaft on the Paint Mixing Machine. This damage requires stopping the production process to make repairs, this causes time and cost loss for the company. The purpose of this study was to find the cause and determine the mechanism of failure that occurred in the Bottom plate mounting shaft with S45C carbon steel material specifications. Fractography results show that the fracture surface is a tempered martensite structure which has a high enough hardness and is brittle so that there is no plastic deformation on the fracture surface, but it can reduce the resistance of the material to unidirectional bending workloads and has a high tension concentration. Then it can be concluded that the damage that occurs to the BottomPlate Mount Shaft from the S45C material on the Paint Mixing Machine is caused by fatigue fractures, this is supported by fracture propagation starting from one side of the shaft and the fatigue area occurs at $3 / 4$ of the diameter of the Bottomplate Mount Shaft.
\end{abstract}

Keywords: Bottom Plate Mount Shaft, Paint Mixing Machine, Damage Analysis, Testing.

\section{PENDAHULUAN}

Gyroscopic Mixer merupakan salah satu bagian dari mesin yang digunakan pada industri cat, untuk menghasilkan produksi cat yang tinggi dengan waktu pembuatan yang relatif lebih singkat daripada dengan proses manual. Pemeliharaan 
dan keandalan (Maintenance and reliability) merupakan aktivitas yang berkaitan untuk mempertahankan peralatan sistem kerja mesin dalam kondisi baik untuk waktu tertentu sehingga tidak mengganggu proses produksi. Dalam BBRM Gyroscopic Mixer (Buku besar riwayat mesin Gyroscopic Mixer) tidak ditemukan standart baku umur poros dudukan bottom plate serta material yang digunakan. Kerusakan yang terjadi pada umumnya Patah, Aus dan Keropos sehingga jika kerusakan tersebut di tunda penggantiannya maka proses pencampuran (mixing) dalam mesin akan menyebabkan kaleng cat akan penyok atau tumpah dan bocor ke sekitar mesin Gyroscopic Mixer.[1]

Dari hasil pengamatan visual pada Gyroscopic Mixer menunjukkan bahwa kerusakan mayoritas terjadi pada area bottom plate yang berfungsi untuk menjepit (clamp) kaleng / pail yang ditopang oleh Poros sebagai titik pusat beban yang diterima. Guna memastikan komposisi material serta faktor - faktor lainnya perlu dilakukan pengkajian umur operasional dengan pengujian laboratorium dan simulasi penggunaan. Pengujian yang dilakukan adalah uji komposisi material, uji kekerasan, dan uji metalografi dan melakukan pengamatan struktur mikro. Dari beberapa pengujian dan analisa yang dilakukan, diharapkan dapat menjadikan referensi pengambilan keputusan yang tepat. Belajar dari kegagalan adalah ungkapan yang populer saat ini menjadikan perkembangan ilmu pengetahuan di bidang teknik pemeliharaan semakin maju. Dalam industri pemeliharaan (maintenance), kegagalan-kegagalan komponen dari alat (component of machine) begitu banyak ditemukan dan mengganggu proses produksi.

Pemeliharaan adalah suatu kombinasi dari berbagai tindakan yang dilakukan untuk menjaga suatu barang dalam, atau memperbaikinya sampai suatu kondisi yang bisa diterima sehingga Pengertian Pemeliharaan lebih jelas adalah tindakan merawat mesin atau peralatan pabrik dengan memperbaharui umur masa pakai dan kegagalan / kerusakan mesin, Kerusakan yang terjadi pada umumnya patah, aus sehingga jika kerusakan tersebut ditunda penggantiannya maka akan menyebabkan patah dan menyebabkan kaleng / pail akan bergeser yang menyebabkan tidak berada pada posisi tengah sehingga membuat getaran yang berlebihan dan membuat barang yang dimixing menjadi tumpah karena penyok. Kerusakan menyebabkan berhentinya proses produksi karena penggantian atau perbaikan memerlukan waktu yang \pm 2 Jam. Kerugian perusahaan akibat kerusakan tersebut meliputi biaya perbaikan, terlambatnya proses produksi lanjutan dan tertundanya pengiriman ke konsumen (customer).

Dari hasil pengamatan visual pada Poros menunjukkan bahwa kerusakan mayoritas terjadi aus pada area dudukan bearing sepanjang permukaan, cacat atau tercoaknya Poros pada bagian dudukan bearing patah. Analisa kerusakan diawali dengan memastikan komposisi material dan faktor - faktor lainnya, serta perlu dilakukan pengkajian melalui tahapan pengujian laboratorium penggunaan FEM. Pengujian laboratorium meliputi uji komposisi material, uji kekerasan, dan uji metalografi. Data - data hasil pemeriksaan dan pengujian diharapkan menjadi referensi analisa kerusakan dan pengambilan keputusan yang tepat.[1]

\section{METODOLOGI}

\section{PROSESDUR PENELITIAN}

Proses penelitian analisa kerusakan Poros Dudukan Bottom Plate material S45C dan studi kelayakan pada operasi Mesin Gyroscopic Mixer. Secara garis besar proses penelitian yang dilakukan untuk mendapatkan akar penyebab kegagalan operasional dan studi kelayakan Poros Dudukan Bottom Plate pada operasi Mesin Gyroscopic Mixer seperti yang terlihat pada (Gambar 1) sebagai berikut : 


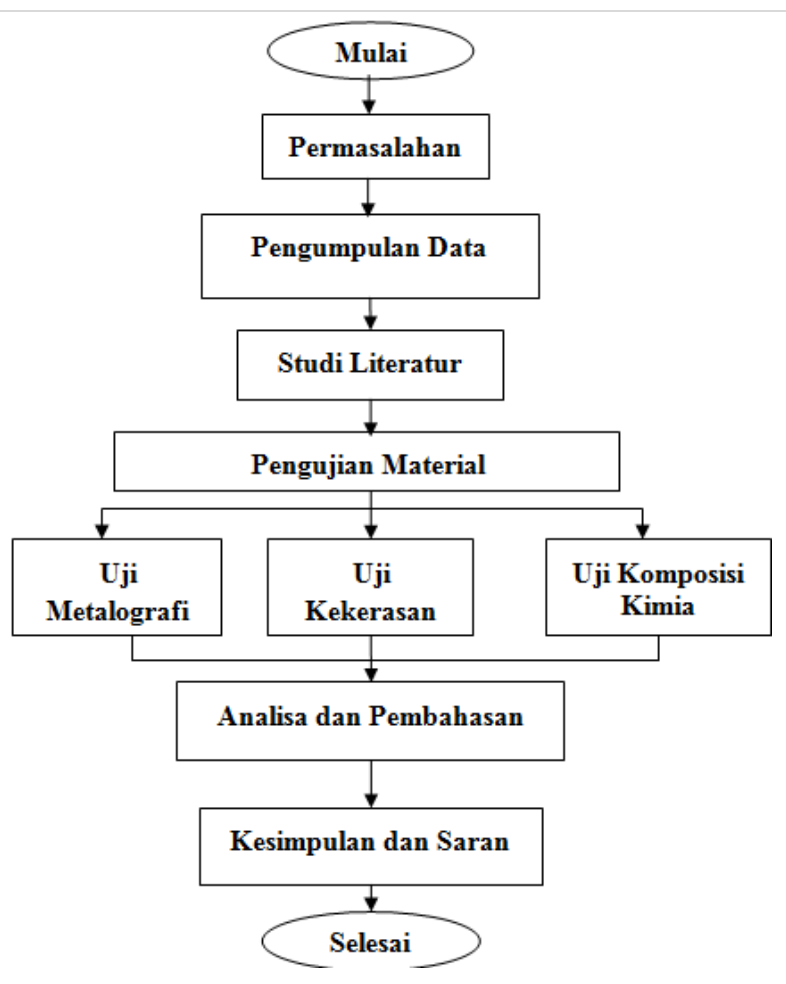

Gambar 1. Diagram alir penelitian

Pengujian laboratorium dilakukan di B2TKS-BPPT Puspiptek Serpong dan Laboraturium Departemen Teknik Metalurgi dan Material, berikut ini pengujian yang dilakukan pada penelitian ini.

\subsection{Pengamatan Visual / Metalografi}

Pengamatan visual yaitu dengan melakukan pemeriksaan secara langsung terhadap material Poros Dudukan Bottom Plate yang mengalami kerusakan dan kegagalan. Untuk mendapatkan data yang lebih akurat dilakukan pengambilan photo pada Poros Dudukan Bottom Plate yang rusak dan komponen-komponen lainnya yang berhubungan dengan sistem operasi Mesin Gyroscopic Mixer tersebut. Pengamatan visual ini penting dilakukan untuk menentukan langkah pemeriksaan berikutnya dari pola kerusakan yang terjadi.

\subsection{Pengujian Komposisi Kimia}

Pemeriksaan komposisi kimia bertujuan untuk mengetahui komposisi material Poros Dudukan Bottom Plate sehingga dapat dilakukan komparasi antara material desain dengan komposisi material Poros Dudukan Bottom Plate secara aktual. Alat yang digunakan untuk pemeriksaan komposisi kimia adalah Optical Emission Spectrometer, yang dilakukan di B2TKS-BPP Teknologi Puspiptek Serpong. Langkah-langah pengujian kimia yang dilakukan sebagai berikut:

a) Pemotongan benda uji.

b) Melakukan gerinda atau pengampelasan pada benda uji.

c) Benda uji dicek apakah kandungan yang terdapat pada material tersebut.

\subsection{Pengujian Kekerasan}

Uji kekerasan (hardness testing) dimaksudkan untuk mengetahui daya tahan Poros Dudukan Bottom Plate 
terhadap deformasi plastis, ketahanan aus serta abrasif pada material. Hasil uji kekerasan digunakan untuk mengetahui nilai kekuatan kekerasan (hardness strength) serta mendeteksi ketahanan material Poros Dudukan Bottom Plate terhadap penetrasi permukaan serta memastikan terjadinya degradasi kekuatan mekanik. Hasil uji kekerasan dibandingkan dengan data literatur untuk mengetahui spesifikasinya detailnya. Beberapa hal yang perlu diperhatikan pada uji kekerasan sebagai berikut :

a) Permukaan sampel uji harus rata dan halus minimal $500 \mathrm{ccw}$

b) Diameter jejak dapat dilihat dan dihitung dengan menggunakan pembesaran melalui mikroskop optik.

Pada pengujian kekerasan Poros Dudukan Bottom Plate ini menggunakan metode pengujian yakni metode skala vickers. Hal ini disebabkan adanya kondisi material yang mengalami pelunakan sehingga dapat dilakukan pengujian dengan skala Vickers (Hv).

\section{HASIL DAN PEMBAHASAN}

Poros dudukan bottom plate merupakan komponen dari Mesin Gyroscopic Mixer yang berfungsi sebagai penopang piringan yaitu tempat untuk menjepit kaleng atau pail serta sebagai dudukan untuk memutar kaleng atau pail Cat dengan putaran yang diinginkan pada display control. Poros dudukan bottom plate terpasang pada bagian bawah (dalam) Mesin Gyroscopic Mixer. Sistem kerja dari bottom Plate sebagai penopang dari rubber plate bawah atau atas, sehingga mempunyai beban terhadap rubber plate dan juga dari proses Clamping dari kaleng atau pail. Kecepatan yang tinggi serta arah yang bolakbalik mampu menjadikan poros tersebut patah atau aus. prinsip kerja sederhana dari mesin gyroscopic mixer yaitu dibagi menjadi 2 langkah, langkah pertama proses menekan (pressing) upper plate dan bottom plate secara bersamaan menekan kaleng atau pail kemudian dilanjutkan dengan langkah kedua proses berputar secara gyroscopic memutar kaleng atau pail Cat yang digerakkan menggunakan v-belt sepeti ditunjukan pada Gambar 2.
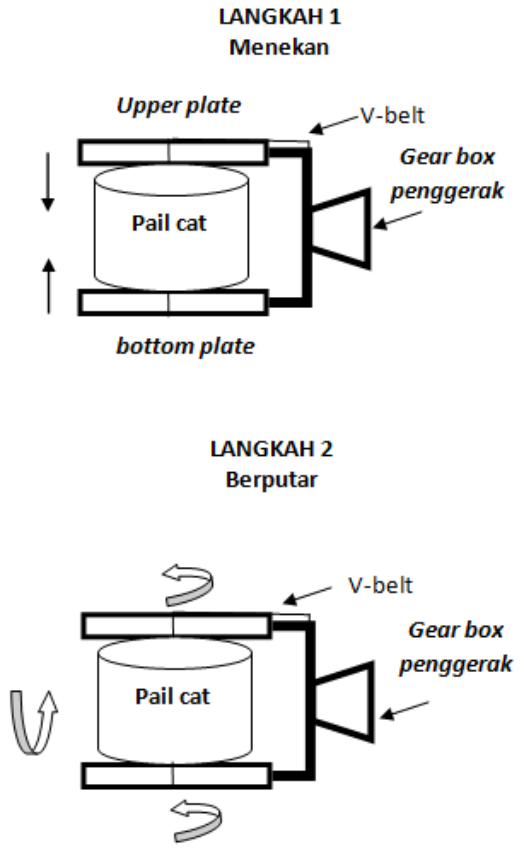

Gambar 2. Mekanisme kerja poros dudukan bottom plate [1]

\section{Analisa Metalografi Poros Dudukan Bottom Plate[7]}

Analisa Metalografi dilakukan untuk mempelajari tentang pemeriksaan logam agar dapat mengetahui adanya perubahan sifat, cacat material, perubahanan struktur material, serta perpindahan panas yang terjadi. 


\subsection{Pemeriksaan struktur makro}

Poros dudukan bottom Plate seperti terlihat pada Gambar 3. yang digunakan sebagai penahan beban untuk mencampur Cat mengalami kegagalan atau kerusakan, patah saat digunakan 6000 jam operasi.

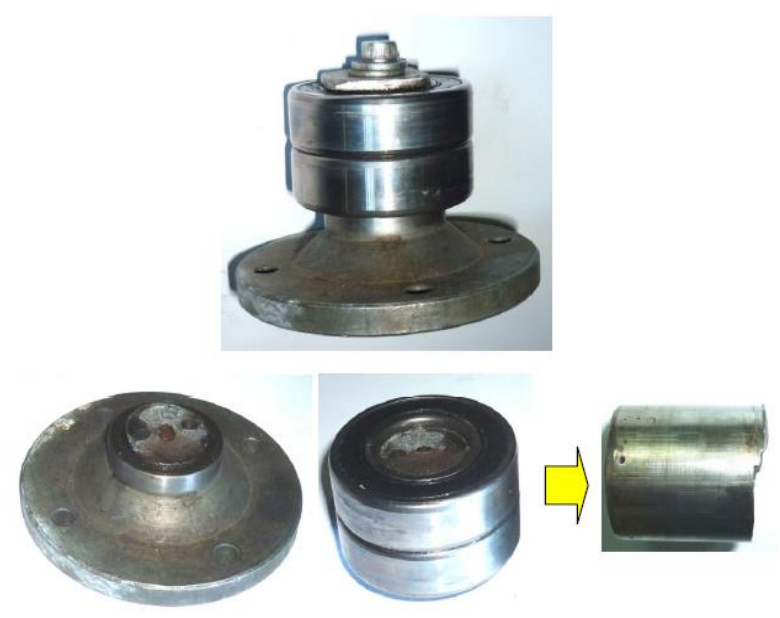

Gambar 3. Hasil pengamatan visual komponen Poros[2]

Kemudian pada (gambar 4. ) menunjukan posisi patah pada daerah radius yang terjadi pada poros dudukan bottom plate yang akan diamati secara makro.

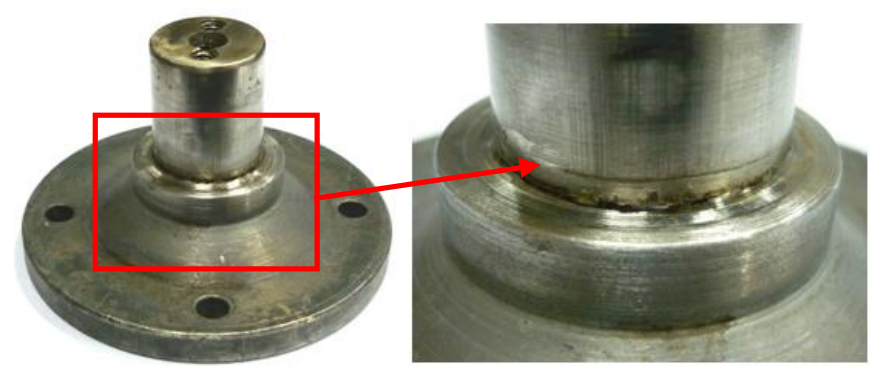

Gambar 4.. Posisi patah pada daerah radius poros

Pada Gambar 5. menunjukkan bahwa Kedua permukaan patahan diamati secara makro menggunakan stereo mikroskop dari perbesaran $6 x, 12 x$ dan $25 x$ 


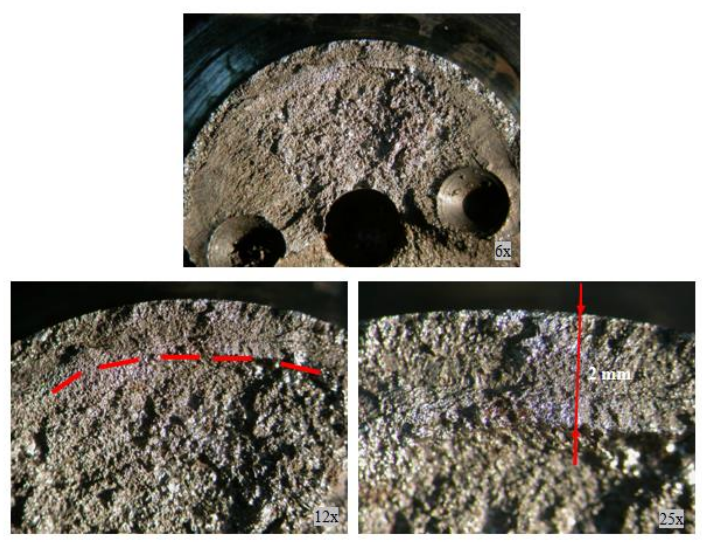

Gambar 5. Pengamatan Perrmukaan patahan

Kemudian Gambar 6. menunjukan Permukaan patahan pada pangkal Poros, 1/2 bagian merupakan patah lelah (farique fracture) yang berawal dari tepi satu sisi (bidang A). Penjalaran patah lelah berhenti disebabkan di lubang baut dan berlanjut kembali (bidang B dan C) sedangkan patah sisa (D) mempunyai permukaan kasar. Pada daerah tepi (E) terdapat indikasi adanya perbedaan jenis material arah melingkar. Jadi jenis permukaan patahan Poros termasuk low nominal stress yang mendapat beban kerja unidirectional bending dan mempunyai severe stress concentration.

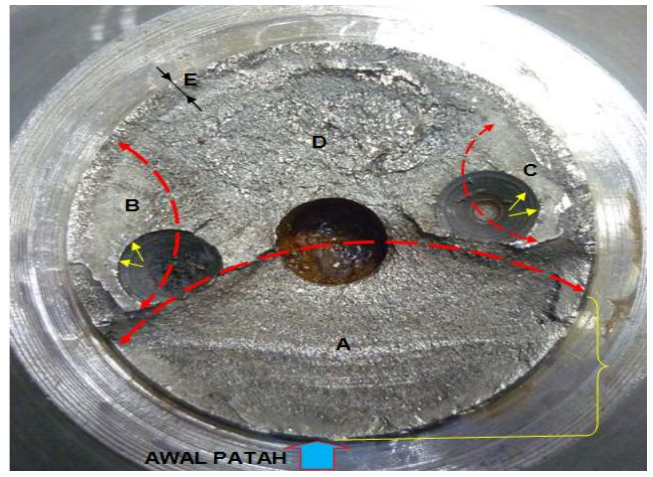

Gambar 6. Photo makro Permukaan patahan pada pangkal Poros

\subsection{Pemeriksaan struktur mikro[3]}

Dari hasil pengamatan secara mikro pada permukaan patahan luar poros yaitu di sekitar area yang dikeraskan seperti ditunjukkan pada (Gambar 7), Pengambilan sampel metalografi potongan memanjang dan hasil makro etsa menggunakan nital $2 \%$ dan etsa kalling reagent.
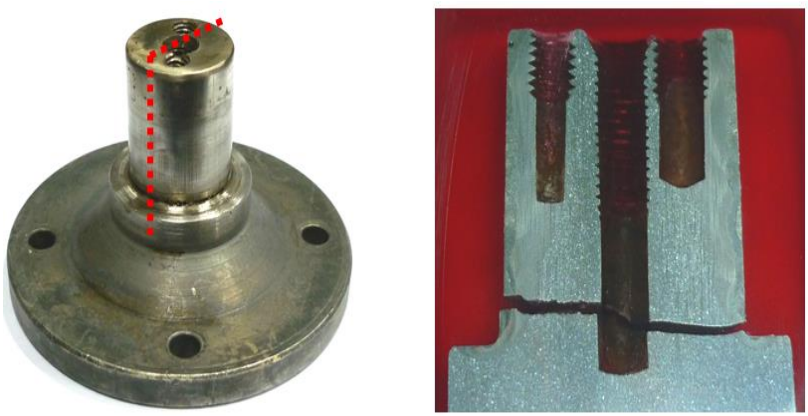

Gambar 7. Potongan sampel metalografi memanjang

Kemudian pada Gambar 8. menunjukan hasil pengamatan secara makrografi atau makro etsa pada sampel potongan memanjang terlihat daerah permukaan mengalami rekondisi dengan material las yang bertujuan pengerasan permukaan untuk 
mencegah terjadinya aus akibat putaran bearing. Pada daerah awal patah terlihat tidak terdapat material las hanya pengaruh panas (HAZ) sedangkan di daerah patah sisa material las cukup tebal $2 \mathrm{~mm}$ seperti terlihat pada photo makro patah sisa.

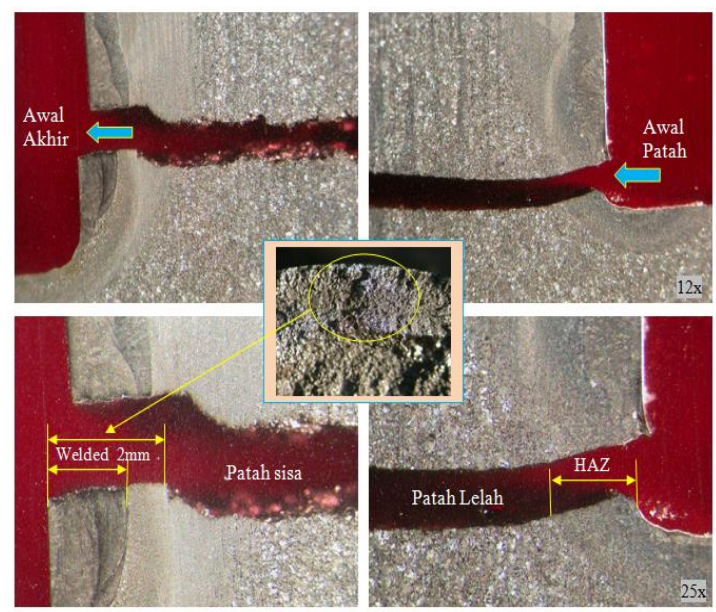

Gambar 8. Hasil pengamatan secara makrografi
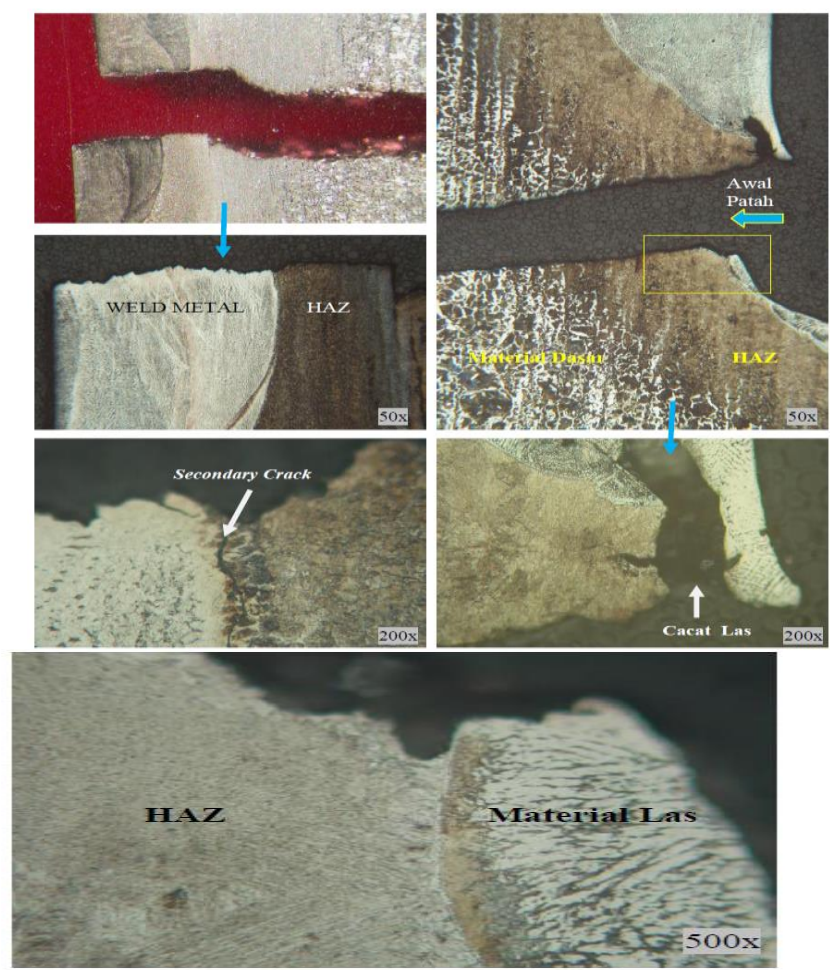

Gambar 9. Hasil Perbesaran 500x dari Gambar 8

Pada Gambar 9. adalah perbesaran dari Gambar 7, pada awal patah terdapat cacat las berupa porosity dan area material las sangat tipis sedangkan di daerah patah sisa material las $2 \mathrm{~mm}$, struktur mikro las berupa martensit dendrite austenit dan butir karbida sedangkan daerah HAZ berupa martensit, pada batas las sisi kiri antara material las dengan HAZ terjadi retak secondary crack. 

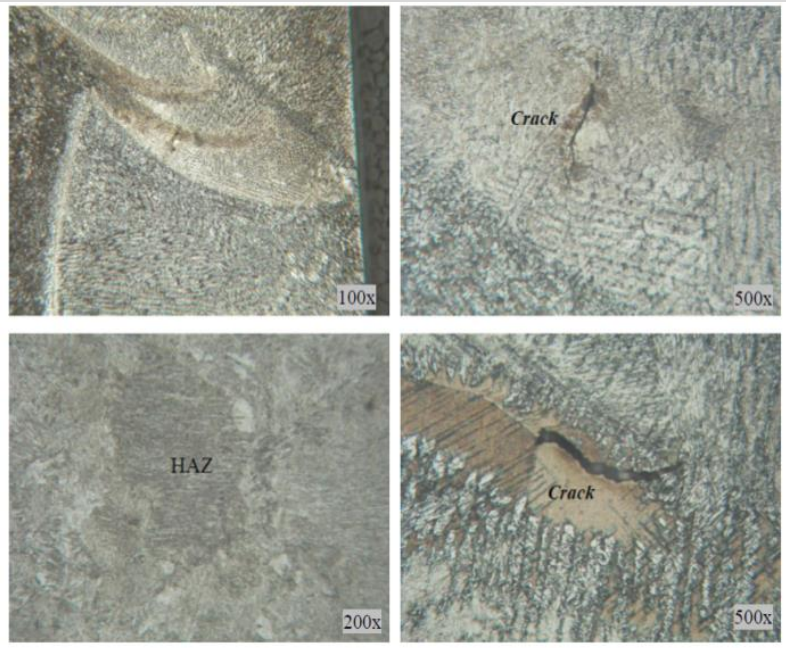

Gambar 10. Cacat retak pada daerah Las

Pada Gambar 10. menunjukkan bahwa Cacat Las berupa retak arah vertical dan horizontal, struktur las berupa martensite dan carbida austenite bentuk dendrite. Posisi yang mengalami retak mikro sejajar awal patah dan dapat dikatakan proses pengelasan tidak sempurna[7].

Struktur HAZ berupa martensit halus, jika diperbesar 200x dan 500x terlihat jelas struktur mikro material dasar yang berwarna putih dan hitam (Gambar 11)

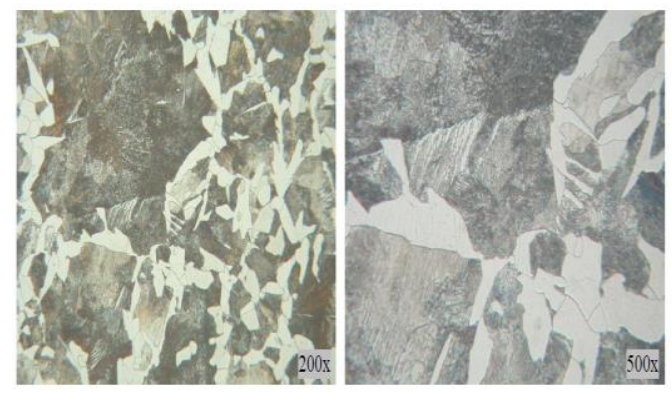

Gambar 11. Struktur mikro ferit (putih) dan perlit (hitam)[4]

\section{b). Analisa Uji Komposisi Kimia}

Berdasarkan hasil pemeriksaan visual, dipandang perlu untuk melakukan pengujian komposisi kimia sebagai berikut : 


\section{Tabel 1 Hasil uji komposisi kimia[6]}

\begin{tabular}{|l|l|l|}
\hline \multirow{2}{*}{ Unsure } & Re su l t (wt \%) & Standart (\%) \\
\cline { 2 - 3 } & Poros & S45C \\
\hline $\mathrm{Fe}$ & 98.3 & 98 \\
\hline $\mathrm{C}$ & 0.519 & $0.42-0.48$ \\
\hline $\mathrm{Si}$ & 0.238 & $0.15-0.35$ \\
\hline $\mathrm{Mn}$ & 0.692 & $0.6-0.9$ \\
\hline $\mathrm{Cr}$ & 0.0344 & - \\
\hline $\mathrm{Ni}$ & 0.0050 & - \\
\hline $\mathrm{Mo}$ & 0.0118 & - \\
\hline $\mathrm{Cu}$ & 0.0125 & - \\
\hline $\mathrm{A} 1$ & 0.0028 & - \\
\hline $\mathrm{V}$ & 0.099 & - \\
\hline $\mathrm{Ti}$ & 0.0014 & $0.035 \mathrm{Max}$ \\
\hline $\mathrm{S}$ & 0.0094 & $0.030 \mathrm{Max}$ \\
\hline $\mathrm{P}$ & 0.0395 & - \\
\hline $\mathrm{Co}$ & 0.0108 & - \\
\hline $\mathrm{Nb}$ & 0.0341 & - \\
\hline $\mathrm{Zr}$ & 0.0041 & - \\
\hline $\mathrm{Pb}$ & 0,0217 & \\
\hline $\mathrm{W}$ & 0.0250 & \\
\hline & & \\
\hline
\end{tabular}

Dari analisa hasil uji komposisi kimia (Tabel 1.) Poros Dudukan Bottom Plate kondisi baru dan yang mengalami kerusakan dapat disimpulkan bahwa:

1) Unsur karbon (C) pada Poros Dudukan Bottom Plate baru (0.519\% C) sesuai dengan standar JIS G5501 2009 (0.42-0.48\%C), memperlihatkan perbedaan komposisi karbon yang significant sehingga Poros Dudukan Bottom Plate terpengaruh efek panas dengan berkurangnya sifat kekerasan, sifat tarik, elongasi, kekuatan impact namun mempercepat titik lebur.

2) Unsur silikon (Si) pada Poros Dudukan Bottom Plate baru (0.238\% Si) sesuai dengan standar JIS G5501 2009 $(0.15-0.35 \% \mathrm{Si})$ sesuai standart sehingga ketahanan material masih dalam tahap toleransi sifat mekanis logam.

3) Unsur sulfur (S) pada Poros Dudukan Bottom Plate baru (0.006\%S) sesuai dengan standar JIS G5501 2007 $(0.15 \% \mathrm{~S})$ namun pada kondisi setengah pakai $(0.002 \% \mathrm{~S})$ dan kondisi rusak $(0.003 \% \mathrm{~S}$ lebih rendah dari standart, dengan rendahnya unsur sulfur (S) pada material Poros Dudukan Bottom Plate maka akan mempengaruhi sifat mampu mesin dan sifat kekerasannya.

Unsur mangan (Mn) pada Poros Dudukan Bottom Plate (0.692\%Mn) sesuai dengan standar JIS G5501 2007 (0.6-0.9 $\% \mathrm{Mn})$. Masih dalam ranah toleransi.

\section{c). Analisa Uji Kekerasan[5]}

Pengujian kekerasan pada Poros Dudukan Bottom Plate bagian dalam dimaksudkan untuk menganalisa perubahan kekerasan akibat Proses pengerasan permukaan, Sampel uji kekerasan diambil masing-masing pada daerah yang mengalami patah atau aus dan daerah yang masih normal. Uji kekerasan tersebut menggunakan metode Hardnes Vickers (HV) dengan beban $5 \mathrm{Kgf}$ dan sudut indentor $136^{\circ}$ seperti terlihat pada Gambar 12. 

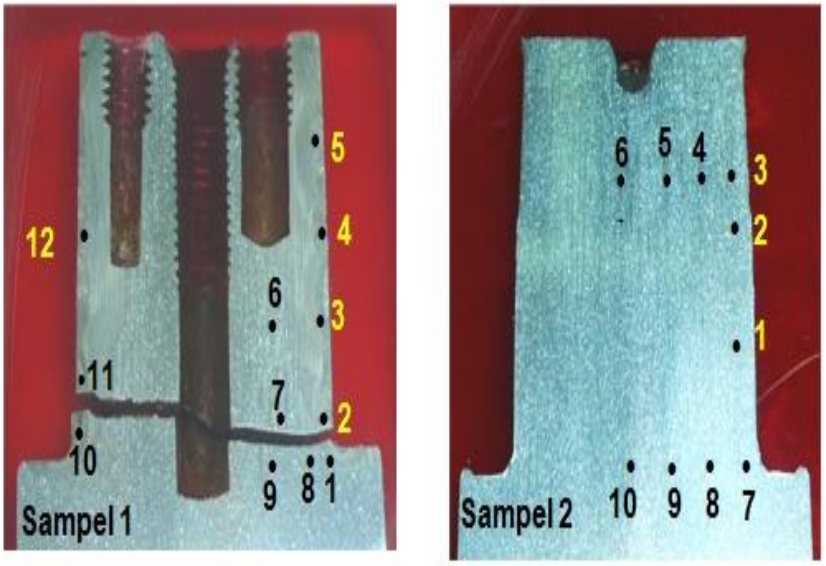

Gambar 12. hasil uji kekerasan

Tabel 2. Hasil Uji Kekerasan

\begin{tabular}{|c|c|c|}
\hline \multirow{2}{*}{} & \multicolumn{2}{|c|}{ NILAI KEKERASAN, HV } \\
\cline { 2 - 3 } & Sampel 1 & Sampel 2 \\
\hline 1 & 460 & 189 \\
\hline 2 & 412 & 181 \\
\hline 3 & 593 & 202 \\
\hline 4 & 576 & 172 \\
\hline 5 & 412 & 166 \\
\hline 6 & 199 & 206 \\
\hline 7 & 195 & 216 \\
\hline 8 & 377 & 187 \\
\hline 9 & 199 & 174 \\
\hline 10 & 689 & 181 \\
\hline 11 & 699 & - \\
\hline 12 & 612 & - \\
\hline
\end{tabular}

Dari (Tabel 2) diatas nilai kekerasan pada permukaan Poros Dudukan Bottom Plate dapat diartikan Sample 1 (nomor 112 ) nilai kekerasan yang naik dari standart, Sample 2 (Nomor 1-10) nilai kekerasan yang sesuai standart. Dengan lokasi uji 12 dan 10 titik dengan data awal sebagai berikut :

1) keadaan sample 1 kekerasan rata - rata sebesar 195-199 HV

2) sedangkan keadaan sudah dilakukan pengerasan permukaan antara $412-699 \mathrm{HV}$ keadaan sample 2 kekerasan rata - rata sebesar 172-216 


\section{KESIMPULAN}

Berdasarkan hasil analisa dan pembahasan dapat diambil beberapa kesimpulan sebagai berikut:

1. Berdasarkan pengamatan visual terhadap Poros yang lokasinya hampir sama (lokasi leher), kerusakan karena posisi dari pail cat yang tidak berada di tengah yang menghasilkan gaya sentrifugal yang lebih besar, sehingga menyebabkan konsentrasi tegangan yang tinggi pada poros bottom plate

2. Mekanisme terjadinya kegagalan Poros dudukan bottom plate mengalami patah lelah (fatique fracture), Penjalaran patah dimulai dari satu sisi shaft dan daerah fatigue terjadi pada $3 / 4$ dari diameter Poros Dudukan Bottom Plate. Jenis permukaan patahan Poros termasuk kelompok low nominal stress yang mendapat beban kerja unidirectional bending dan mempunyai severe stress concentration.

3. Adanya usaha rekondisi poros agar tidak terjadi aus, dengan adanya pengelasan pada bagian luar polos, karena sudah ada bukti pengelasan pada Gambar 9

4. Adanya penambahan lubang untuk baut penahan poros, sehingga menyebabkan luas penampang poros menjadi kecil

5. Hasil uji kekerasan menunjukan adanya proses pengelasan yang tidak sempurna.

6. Hasil komposisi material poros sesuai dengan standar S45C, sehingga tidak perlu dilakukan perubahan material.

Saran :

Untuk menyempurnakan hasil penelitian ini, ada beberapa hal yang perlu dipertimbangkan adalah:

1) Perlu dilakukan pengkajian kembali secara lebih detail dalam pemilihan disain, pemasangan Poros Dudukan Bottom Plate terhadap ketahanan gesekan.

2) Hasil pemeriksaan dan pengujian yang telah dilakukan terhadap poros dudukan bottom plate kondisi patah maka untuk menanggulangi hal tersebut disarankan material poros (S45C) untuk dilakukan proses heat treatment dan kemudian ditemper agar ulet atau kuat dan homogen serta dilakukan proses pengerasan permukaan (case hardning layer) pada bagian poros yang bergesekan.

3) Dibuatkan disain cetakan piringan rubber plate untuk menempatkan pail cat pada posisi tengah ( Centre)

Diperlukan upaya peningkatan dan optimasi kinerja mesin, simplikasi atau proses otomatis, efisiensi proses produksi dan lebih meningkatkan pemahaman manajemen pemeliharaan, meliputi jenis perawatan, penyesuaian spesifikasi mesin, pengujian dan analisa kerusakan serta pencegahannya.

\section{DAFTAR PUSTAKA}

[1] HPU, 2017. Hand book Gyroscopic Mixer 5T.

[2] Chameleon, 2011. Hand book iMix Gyroscopic Paint Mixer Instruction Manual, UM013 iMix Rev.3 .

[3] Daryanto, Bandung 2010. Ilmu Metalurgy. Satu nusa.

[4] Andi, Padang, 2013. Anrinal, Metalurgi fisik.

[5] http://ejurnalmaterialmetalurgi.com/index.php/metalurgi/article/download/255/122 diakses pertanggal 04 Agustus 2018

[6] http://www.astmsteel.com/product/c45-round-bar-aisi-1045-din-jis-s45c/ diakses pertanggal 04 Agustus 2018

[7] D,N. Adnyana, 2003. Struktur dan Sifat Mekanis Material Logam, Diktat Mata Kuliah Program Pasca Sarjana (S2) ISTN Jakarta. 